\title{
Cloacal swabs and alcohol bird specimens are good proxies for compositional analyses of gut microbial communities of Great tits (Parus major)
}

\author{
Kasun H. Bodawatta ${ }^{1 *}$, Katerina Puzejova ${ }^{2,3}$, Katerina Sam²,3, Michael Poulsen ${ }^{4}$ and Knud A. Jønsson ${ }^{1}$
}

\begin{abstract}
Background: Comprehensive studies of wild bird microbiomes are often limited by difficulties of sample acquisition. However, widely used non-invasive cloacal swab methods and under-explored museum specimens preserved in alcohol provide promising avenues to increase our understanding of wild bird microbiomes, provided that they accurately portray natural microbial community compositions. To investigate this assertion, we used $16 \mathrm{~S}$ rRNA amplicon sequencing of Great tit (Parus major) gut microbiomes to compare 1) microbial communities obtained from dissected digestive tract regions and cloacal swabs, and 2) microbial communities obtained from freshly dissected gut regions and from samples preserved in alcohol for 2 weeks or 2 months, respectively.

Results: We found no significant differences in alpha diversities in communities of different gut regions and cloacal swabs (except in OTU richness between the dissected cloacal region and the cloacal swabs), or between fresh and alcohol preserved samples. However, we did find significant differences in beta diversity and community composition of cloacal swab samples compared to different gut regions. Despite these community-level differences, swab samples qualitatively captured the majority of the bacterial diversity throughout the gut better than any single compartment. Bacterial community compositions of alcohol-preserved specimens did not differ significantly from freshly dissected samples, although some low-abundant taxa were lost in the alcohol preserved specimens.

Conclusions: Our findings suggest that cloacal swabs, similar to non-invasive fecal sampling, qualitatively depict the gut microbiota composition without having to collect birds to extract the full digestive tract. The satisfactory depiction of gut microbial communities in alcohol preserved samples opens up for the possibility of using an enormous resource readily available through museum collections to characterize bird gut microbiomes. The use of extensive museum specimen collections of birds for microbial gut analyses would allow for investigations of temporal patterns of wild bird gut microbiomes, including the potential effects of climate change and anthropogenic impacts. Overall, the utilization of cloacal swabs and museum alcohol specimens can positively impact bird gut microbiome research to help increase our understanding of the role and evolution of wild bird hosts and gut microbial communities.
\end{abstract}

Keywords: Non-invasive sampling, Museum alcohol bird collections, Microbiomes, Passeriformes, Digestive tract microbiota

\footnotetext{
* Correspondence: bodawatta@snm.ku.dk

${ }^{1}$ Natural History Museum of Denmark, University of Copenhagen,

Copenhagen, Denmark

Full list of author information is available at the end of the article
}

(C) The Author(s). 2020 Open Access This article is licensed under a Creative Commons Attribution 4.0 International License, which permits use, sharing, adaptation, distribution and reproduction in any medium or format, as long as you give appropriate credit to the original author(s) and the source, provide a link to the Creative Commons licence, and indicate if changes were made. The images or other third party material in this article are included in the article's Creative Commons licence, unless indicated otherwise in a credit line to the material. If material is not included in the article's Creative Commons licence and your intended use is not permitted by statutory regulation or exceeds the permitted use, you will need to obtain permission directly from the copyright holder. To view a copy of this licence, visit http://creativecommons.org/licenses/by/4.0/. 


\section{Background}

Appropriate sample collection and preservation methods are important when investigating symbioses between hosts and their gut microbes [1-4]. Although the use of entire digestive tracts of freshly obtained specimens is ideal to characterize and capture the full diversity and relative abundances of bacteria residing within guts [2, 5-7], the acquisition of full digestive tracts is often problematic in many vertebrate groups. This is especially true in wild birds and mammals due to permit limitations and ethical issues [8]. Consequently, many mammalian and avian microbiome studies utilize non-invasive methods (e.g., feces or cloacal swabs) [2, 9-11], which also provide opportunities to explore rare and endangered animals without negatively affecting host populations [12-15].

Most bird microbiome studies have utilized feces (e.g., $[11,13,14,16-20]$ ) or cloacal swabs (e.g., [21-29]), but a handful of studies have demonstrated that bacterial communities are compartmentalized across different digestive tract regions $[2,5,30,31]$. This questions whether noninvasive methods only capture fecal and cloacal bacterial communities. The small number of studies that have investigated the validity of non-invasive sampling methods to characterize bird gut microbiomes have shown that non-invasive methods consequently only represent gut microbiome compositions qualitatively [2, 32, 33]. This implies that we must be cautious in our conclusions about full gut community structure when utilizing non-invasive approaches, but at the same time emphasizes that noninvasive methods can identify symbiont lineages present within guts. Such validation studies have however only been conducted on a few non-passerine bird species [2, 32, 33], and we thus lack similar analyses from diverse clades such as the passerines. If easily-acquirable cloacal swabs adequately portray wild bird gut microbiomes, this could facilitate more studies and increase our understanding of wild bird-gut microbial symbioses [9, 34-36].

Another possible source of wild birds for digestive tract microbiome analyses is alcohol specimens stored in museums $[37,38]$. European museums alone house more than 78,000 specimens [39], and around 45,000 specimens are housed in North America [40] and 22,000 in Australia and New Zealand [41]. Although sampling entire guts from alcohol specimens is not non-invasive, the utilization of these enormous unexplored collections would provide promising opportunities to investigate microbial communities, provided that they reliably portray gut microbial community compositions of freshly dissected digestive tracts.

To evaluate the accuracy of cloacal swabs and alcohol specimens to characterize gut microbiomes, we investigated gut microbial communities of Great tits (Parus major). First, we compared microbial communities (using 16S rRNA amplicon sequencing) from cloacal swabs with freshly dissected gut regions to validate the use of cloacal swabs to characterize the bacterial communities in the entire digestive tract. Secondly, we compared microbial communities in freshly dissected gut regions with gut sections that had been stored for two-weeks and two-months in alcohol to investigate the potential effect of alcohol preservation on gut microbial communities.

\section{Results}

\section{Microbial community composition differences between} freshly dissected gut regions and cloacal swabs

Using amplicon sequencing of the $16 \mathrm{~S}$ rRNA gene, we acquired 1,055,295 (mean \pm SE: 17,300 \pm 2798 ) sequences from freshly dissected gut regions and cloacal swabs, which classified into 2189 operational taxonomic units (OTUs) at the 97\% similarity level (Additional file 1: Table S1). Bacterial OTU richness (One-way ANOVA: $\mathrm{F}_{6,54}=2.556, p=$ 0.029: Fig. 1a) and Chao1 richness estimates (One-way ANOVA: $\mathrm{F}_{6,54}=2.445, p=0.0365$; Fig. $1 \mathrm{~b}$ ) only differed significantly between cloacal swabs and the cloacal region (Fig. 1a, b). Shannon's diversity index (One-way ANOVA: $\mathrm{F}_{6,54}=1.059, p=0.398$; Fig. 1c) and Simpson's inverse diversity index (One-way ANOVA: $\mathrm{F}_{6,54}=1.376, p=0.241$; Fig. 1d) did not differ between gut sections and cloacal swabs. Overall, $84.1 \%$ of the total number of OTUs belonged to the phylum Firmicutes, while Proteobacteria accounted for $7.5 \%$, Bacteroidetes $3.8 \%$ and Actinobacteria $2.3 \%$. There was a relative decrease of Proteobacteria in the midgut sections (middle of small intestine: $2.2 \%$, ileum: 2.5\%, large intestine: $4.8 \%$ ) compared to the stomach (9.1\%), the cloaca (15.2\%) and cloacal swabs (32.6\%). Compared to the different digestive tract regions, cloacal swabs represented the diversity of the bacterial communities in the whole digestive tract at the phylum level (Fig. 2a). The 25 most common OTUs accounted for $89.5 \% \pm 1.3 \%$ (mean $\pm \mathrm{SE}$ ) of the sequences, and cloacal swabs qualitatively represented these major bacterial OTUs from the different digestive tract regions (Fig. 2b).

We found a significant difference in bacterial community composition between gut sections (including cloacal swabs) [PERMANOVA 999 permutations (Bray-Curtis): $\mathrm{F}_{6,54}=1.82$, $\left.R^{2}=0.1682, p=0.001\right]$. Community composition did not differ significantly between digestive tract regions; however, cloacal swab bacterial communities differed significantly from four out of six gut regions (Table 1). These community-level differences remained present even after merging results from different gut compartments into three major gut regions (the stomach, the midgut [the small intestine and the cecum], and the hindgut [the large intestine and the cloaca]; Additional file 2: Table S2 and Fig. 3). To qualitatively compare the bacterial communities, we conducted PERMANOVA analyses using the Jaccard distance matrix (based on presence/absence data). Even though the analyses revealed significant qualitative differences in microbial communities among gut sections (including cloacal 


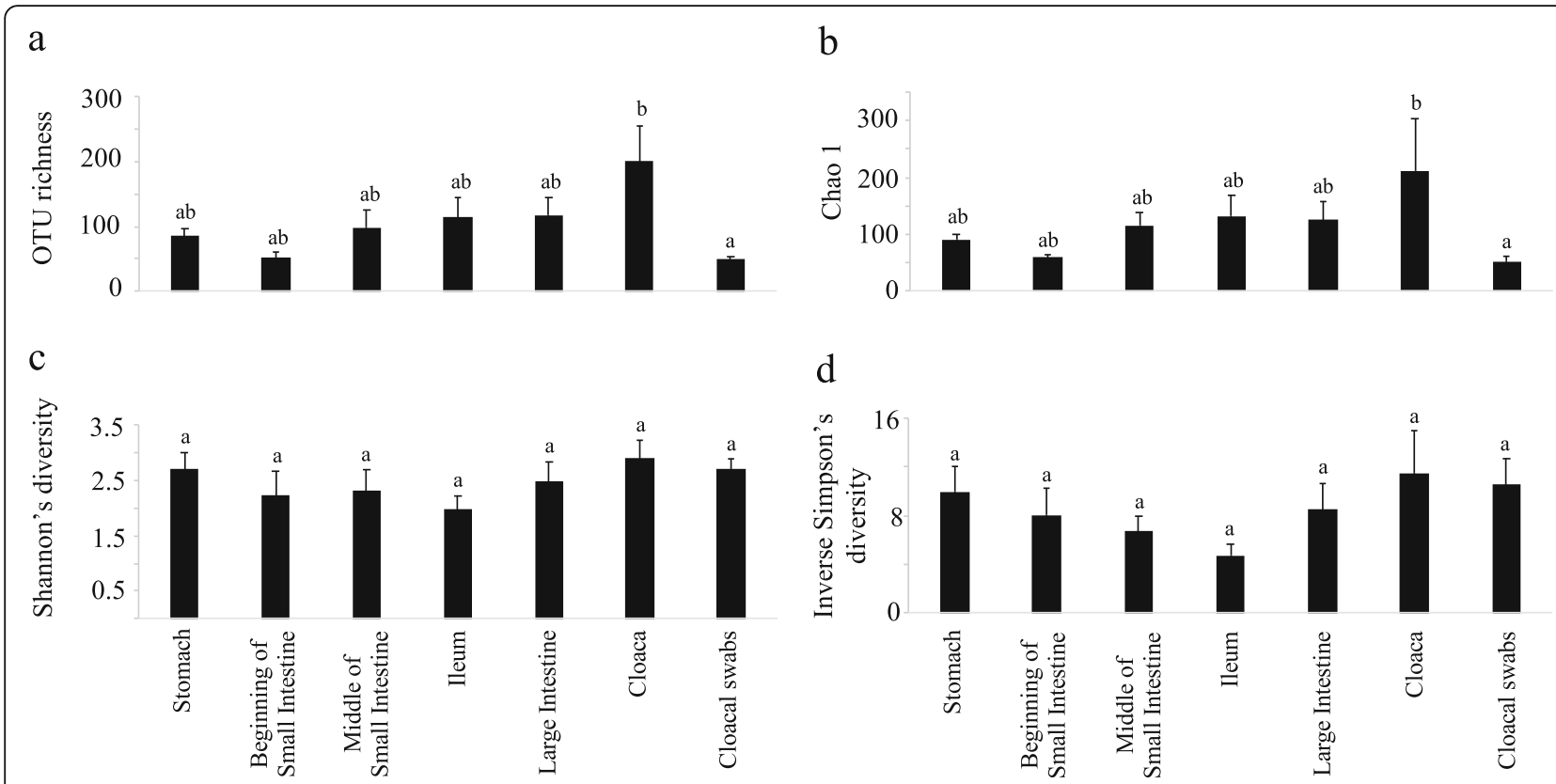

Fig. 1 Average (a) OTU richness, (b) Chao 1 richness estimates, (c) Shannon's diversity index and (d) Inverse Simpson's diversity index of different digestive tract regions and cloacal swab microbial communities. Letters on top of each bar represent the results from the Tukey post hoc test and similar letters represent non-significant groups

swabs) [PERMANOVA999permutations (Jaccard): $\mathrm{F}_{6,54}=1.44$, $\left.R^{2}=0.1383, p=0.001\right]$, the pairwiseAdonis showed that swabs differed significantly from the large intestine and the ilium (Additional file 2: Table S3).

\section{Microbial community composition differences between fresh and alcohol specimens}

We generated 1,904,813 16S rRNA amplicon sequences (mean \pm SE: 29,048 \pm 3057) from the gut sections of bird alcohol specimens, which classified into 2933 OTUs (Additional file 1: Table S1). Similar to the fresh samples, microbial communities of alcohol specimens were dominated by Firmicutes (88.0\%) followed by Proteobacteria (6.16\%). OTU richness, Chao1 richness estimate, Shannon's and inverse Simpson's diversity indices did not differ in any of the six gut regions between freshly directed samples, and both two-weeks and two-months old alcohol specimens (Fig. 4 and Additional file 2: Table S4). Overall, phylumlevel relative abundances of Bacteroidetes and Actinobacteria decreased in multiple gut sections between fresh and two months old alcohol specimens (Fig. 5a). Despite the high individual variation in gut microbiomes, the 15 most common bacterial genera per gut section were present in both fresh and alcohol specimens (Fig. 5b). The bacterial community compositions of different gut regions did not differ significantly between fresh and alcohol specimens, except between the fresh and twomonth old (alcohol specimen) ileal microbiota (Table 2 and Additional file 3: Figure S1).
Multiple DeSeq2 comparisons of microbial communities of freshly dissected and comparable gut sections in differently-aged alcohol specimens revealed only relatively few significantly differentially abundant bacterial genera (Fig. 6 and Additional file 4: Table S5). Only 72 out of 431 genera that were identified to genus-level were significantly differentially abundant in all gut regions between fresh and two-weeks old alcohol specimens, with each gut compartment accounting for on average 14.33 (SE \pm 3.09$)$ differentially abundant genera. Between fresh and two-months old alcohol gut sections, total of 55 taxa that identified to genus level were differentially abundant (mean differentially abundant genera per gut section \pm SE: $15.16 \pm 3.71$ ). Of all differentially abundant genera, only Bacillus significantly increased in relative abundance in all gut sections of two-months old alcohol specimens compared to fresh samples, and the genus Macrococcus was more abundant in fresh compared to two-months old samples in all gut sections except the large intestine (Fig. 6).

\section{Discussion}

We explored the appropriateness of using cloacal swabs and museum alcohol preserved specimens to investigate the gut microbial communities of wild birds. We first demonstrated that digestive tract regions of wild $P$. major differ in gut microbial communities, but that these differences are not as prominent as previous studies have documented in other bird species [2, 5, 30, 31]. While compositions differed between cloacal swabs and different gut regions, 


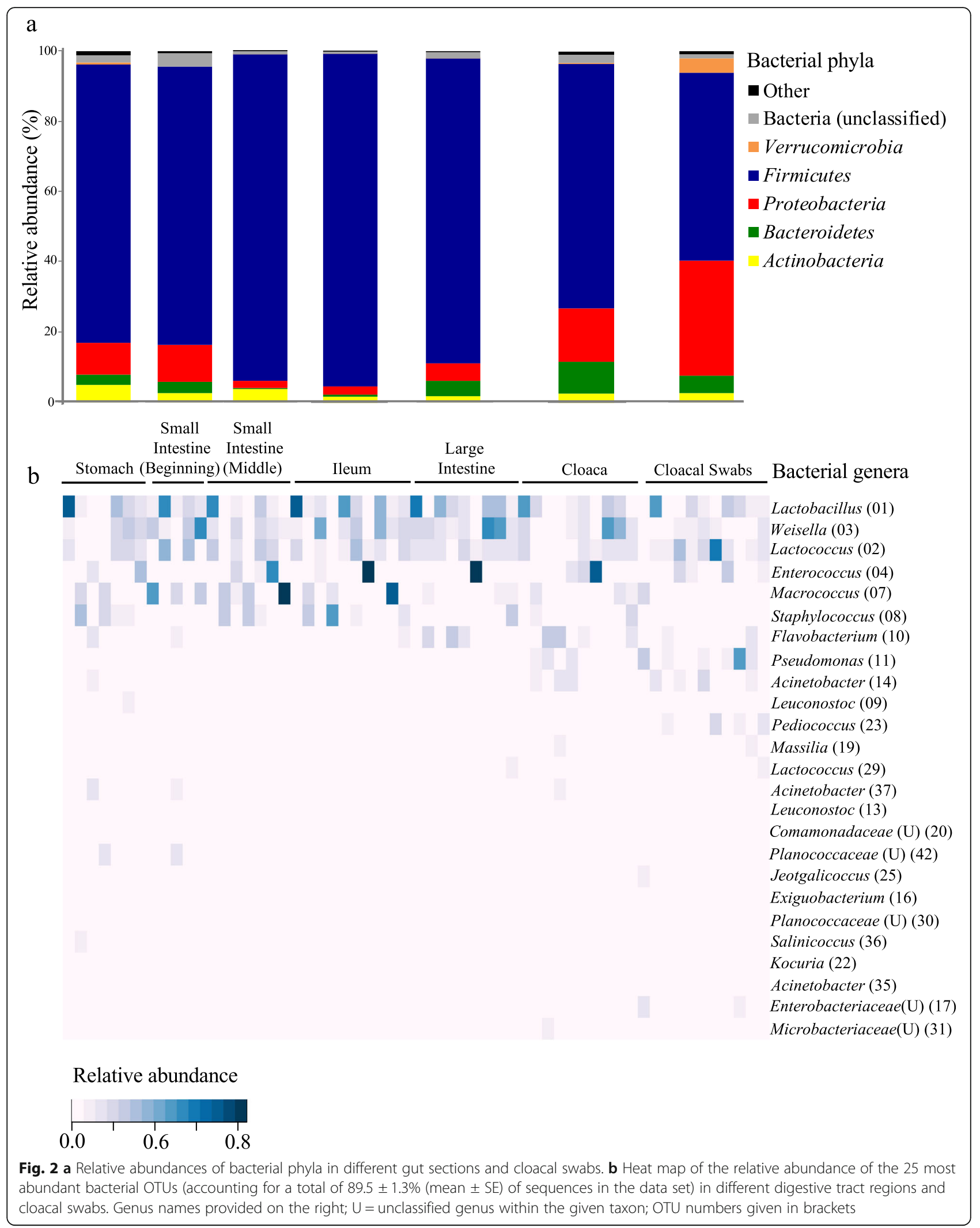


Table 1 The results of pairwiseAdonis analyses (Bray-Curtis distances) between gut microbial communities of different regions of the digestive tract, including cloacal swabs

\begin{tabular}{|c|c|c|c|}
\hline Comparisons & $F$ & $R^{2}$ & $P$ adjusted \\
\hline Swabs vs. Cloaca & 3.576 & 0.1517 & $0.0420^{*}$ \\
\hline $\begin{array}{l}\text { Swabs vs. Large } \\
\text { Intestine }\end{array}$ & 3.809 & 0.1599 & $0.0210^{*}$ \\
\hline Swabs vs. Ilium & 4.164 & 0.1723 & $0.0210^{*}$ \\
\hline $\begin{array}{l}\text { Swabs vs. Middle } \\
\text { of Small Intestine }\end{array}$ & 2.182 & 0.1137 & 0.0630 \\
\hline $\begin{array}{l}\text { Swabs vs. Beginning } \\
\text { of Small intestine }\end{array}$ & 1.779 & 0.1128 & 0.3990 \\
\hline Swabs vs. Stomach & 2.425 & 0.1187 & $0.0210^{*}$ \\
\hline $\begin{array}{l}\text { Cloaca vs. Large } \\
\text { Intestine }\end{array}$ & 0.6861 & 0.0367 & 1 \\
\hline Cloaca vs. Ilium & 1.042 & 0.0547 & 1 \\
\hline $\begin{array}{l}\text { Cloaca vs. Middle } \\
\text { of Small Intestine }\end{array}$ & 1.569 & 0.0946 & 1 \\
\hline $\begin{array}{l}\text { Cloaca vs. Beginning } \\
\text { of Small intestine }\end{array}$ & 2.024 & 0.1443 & 0.5880 \\
\hline Cloaca vs. Stomach & 1.783 & 0.1003 & 0.9240 \\
\hline Large Intestine vs. Ilium & 0.5702 & 0.0307 & 1 \\
\hline $\begin{array}{l}\text { Large Intestine vs. } \\
\text { Middle of Small Intestine }\end{array}$ & 1.421 & 0.0865 & 1 \\
\hline $\begin{array}{l}\text { Large Intestine vs. } \\
\text { Beginning of Small } \\
\text { intestine }\end{array}$ & 1.720 & 0.1254 & 1 \\
\hline $\begin{array}{l}\text { Large Intestine vs. } \\
\text { Stomach }\end{array}$ & 1.440 & 0.0826 & 1 \\
\hline $\begin{array}{l}\text { Ilium vs. Middle of } \\
\text { Small Intestine }\end{array}$ & 0.9653 & 0.0605 & 1 \\
\hline $\begin{array}{l}\text { llium vs. Beginning of } \\
\text { Small intestine }\end{array}$ & 1.720 & 0.1254 & 0.5880 \\
\hline Ilium vs. Stomach & 1.391 & 0.0799 & 0.9240 \\
\hline $\begin{array}{l}\text { Middle of Small } \\
\text { Intestine vs. } \\
\text { Beginning } \\
\text { of Small intestine }\end{array}$ & 0.8934 & 0.0903 & 1 \\
\hline $\begin{array}{l}\text { Middle of Small } \\
\text { Intestine vs. Stomach }\end{array}$ & 0.6036 & 0.0444 & 1 \\
\hline $\begin{array}{l}\text { Beginning of Small } \\
\text { intestine vs. Stomach }\end{array}$ & 0.8747 & 0.0804 & 1 \\
\hline
\end{tabular}

*indicate significantly different groups

swabs qualitatively portrayed bacterial community compositions in the entire digestive tract, aligning with a previous study of a captive bird species [32], as well as reflected gut community compositions from a previous study of wild $P$. major fecal samples [16]. Microbial communities of alcohol-preserved gut regions did not differ significantly from fresh samples, supporting that museum collections represent a promising resource for analyses of gut microbiomes [37]. Notably, the relative low number of differentially abundant genera in freshly dissected and alcohol preserved specimens only marginally impacted the overall microbial community composition across digestive tract regions.
The possibility of determining the qualitative composition of bird gut microbial communities through cloacal swab sampling support that utilization of this noninvasive method to characterize bird microbiomes is appropriate, despite its quantitative limitations [32, 33]. Cloacal swabs did not capture a few rare bacterial taxa. This is evident from a significant difference only in OTU richness (Fig. 1a and b) but not in diversity indexes that account for both abundance and evenness (Fig. 1c and d). The ability of cloacal swabs to capture the majority of common bacterial taxa (Fig. 2) implies that the method would allow for the vast majority of gut symbionts to be identified. Previous work has suggested that fecal sampling better represents gut community compositions than cloacal swabs [2]. Although we did not compare fecal samples with cloacal swabs, the bacterial taxa we acquired from cloacal swabs were similar to taxa characterized in fecal microbiomes of wild $P$. major in a previous study [16], suggesting that microbiome discrepancies between these sampling methods are minor. However, the cloacal swab approach also reduces the risk of contamination and removes the problems associated with the typically lower DNA yield from extractions of bird feces [42, 43].

The observed similarity of gut microbial communities in fresh and alcohol preserved specimens opens of for the possibility of utilizing the vast number of museum bird alcohol specimens [37]. Although we did observe high individual variation in microbial communities, which is common in bird gut microbiomes [13, 16, 37, 44], the most common bacterial genera did not differ significantly between preservation methods (Fig. 4). The slight reduction in the relative abundance of members of the phyla Bacteroidetes and Actinobacteria in alcohol preserved specimens could be due to degradation of bacterial DNA. In addition, it may be that ethanol adversely affects DNA extraction, but a previous study suggests that this has a minimal impact on microbial community characterizations [4]. The genera that were differentially abundant between alcohol preserved and fresh specimens were inconsistent across different gut regions, suggesting that they are unlikely to be caused by the alcohol preservation, but rather are due to the naturally high variation between individuals in passerine bird gut microbiomes [16, 37]. Overall, alcohol preserved specimens thus provide a reliable estimate of gut microbial communities, even after two months of storage.

The utilization of museum specimens to investigate wild bird gut microbiomes would allow substantial insights into bird-microbial symbiosis in multiple ways. First, museum collections provide an opportunity to investigate gut microbiomes of a vast number of extant and extinct wild bird species [38-41] to improve our understanding of the ecology and evolution of birds and 

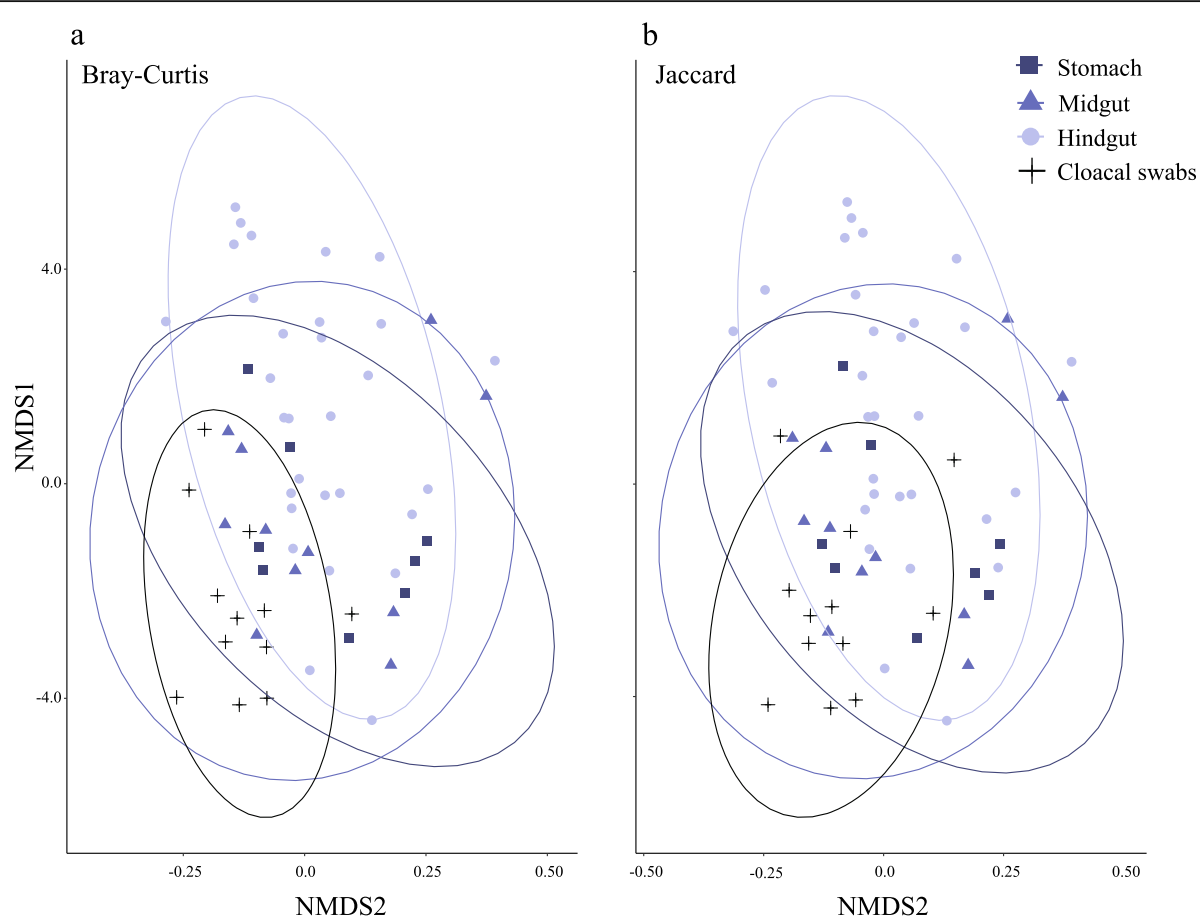

Fig. 3 NMDS plots representing gut microbial community similarities based on $\mathbf{a}$ Bray-Curtis and $\mathbf{b}$ Jaccard distances of the stomach, the midgut (beginning of small intestine, middle of small intestine, ileum), the hindgut (the large intestine and the cloaca) and cloacal swabs. Gut sections were merged into major gut regions to increase clarity of the ordination. Ellipses represent $95 \%$ confidence intervals

their gut microbial symbionts. Secondly, museum collections usually also include individuals from multiple geographic regions, allowing insights into host-symbiont biogeography. Finally, collections typically include a long temporal span, enabling investigations into how bird-gut microbial associations change over time. This would allow us to establish natural temporal changes in associations, but also to test for the effects of climate change and habitat alterations caused by anthropogenic effects. Notably, most museum alcohol specimens are older than two months and longer-term effects of preservations on gut microbiome will thus also be needed. New specimen collections should ideally also focus on preserving the entire animal in alcohol (instead of focusing solely on skins and skeletons) and in storage conditions optimal for the possibility of using these collections for microbiome studies [38].

\section{Conclusions}

Our findings demonstrate that cloacal swabs and museum alcohol specimens are reliable to qualitatively characterize gut microbiome compositions in wild birds. Both methods have limitations but also the potential to markedly improve our understanding of symbioses between wild birds and their gut microbial communities. The ease of cloacal sampling reduces issues related to low sample sizes or sampling from threatened species and may thus help strengthen both population and community-level host microbiome studies. The similarity of gut microbiomes of alcohol preserved and fresh samples provides the possibility of using underexplored museum bird collections to investigate gut microbiomes of a plethora of bird species across the globe and time.

\section{Methods}

\section{Sample collection}

Nineteen adult individuals of $P$. major (captured as fledglings in Ceske Budejovice, the Czech Republic) were kept in individual cages on a daily standard diet consisting of 10 mealworms, $2 \mathrm{~g}$ insect cake [45] a bread-like diet made from - Nutribird a21, commercial chicken food (Country's Best Show 1 crumble), eggs, wheat flower, sugar and sunflower margarine, mixed and baked for $\sim 40 \mathrm{~min}$ at $180^{\circ} \mathrm{C}$ temperature] and 2tsp of moistened mixed seeds (Living World Premium Mix for Cockatiels \& Lovebirds) at the Faculty of Science, University of South Bohemia, Ceske Budejovice, Czech Republic. Cages were cleaned and individuals were given fresh water and food daily. One day before the euthenization of individuals to extract the entire digestive tract or converting them into alcohol specimen, cloacal swabs were collected using a mini FLOQ swabs ${ }^{\text {Tw }}$ (Copan, Italy) and stored in RNAlater at $-21^{\circ} \mathrm{C}$. Cloacal swabs were acquired from the individuals 1 day prior to the euthenization to ensure that the cloacal swab sampling did not have an impact on the microbiome of freshly dissected and alcohol preserved cloacal regions. Individuals were 


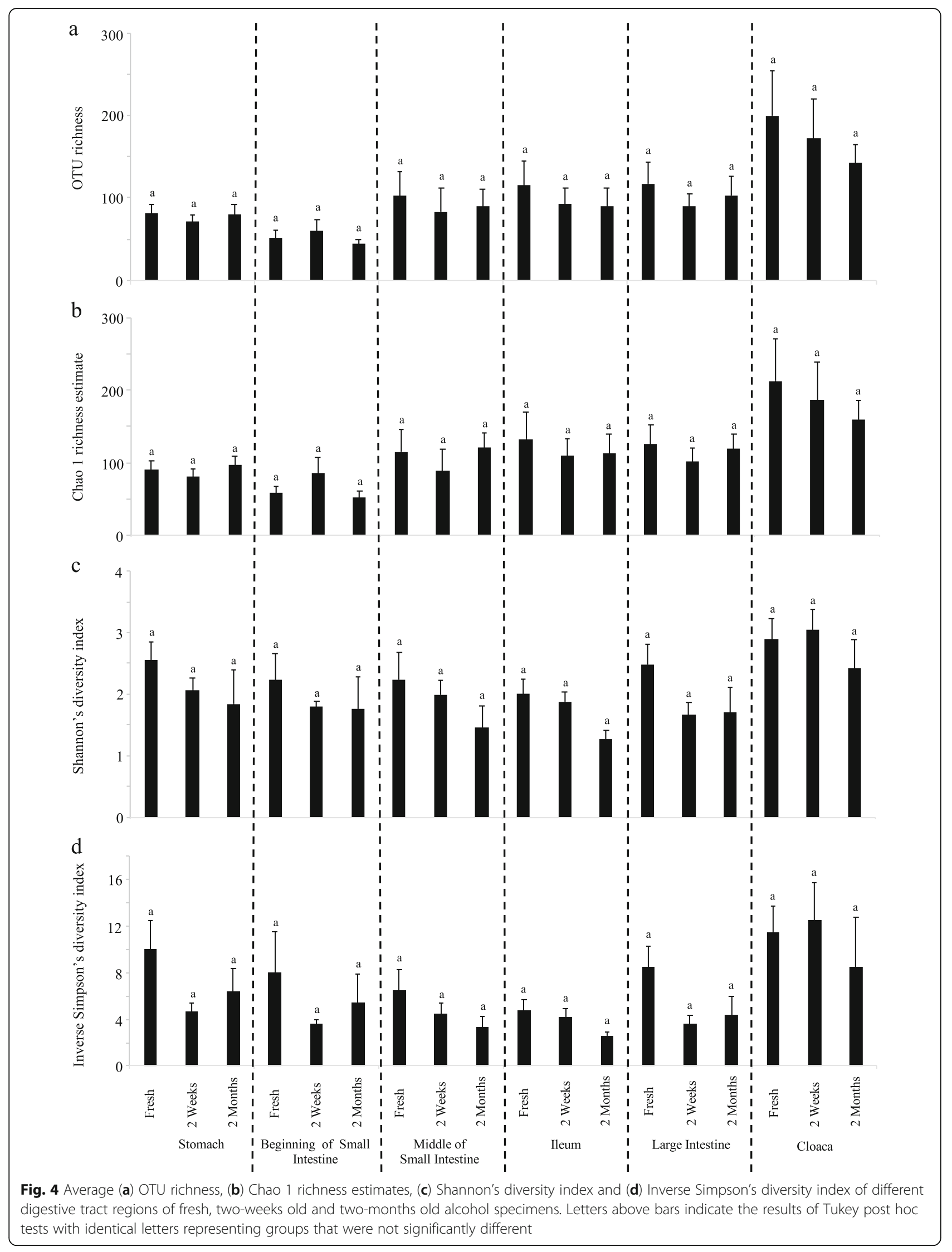




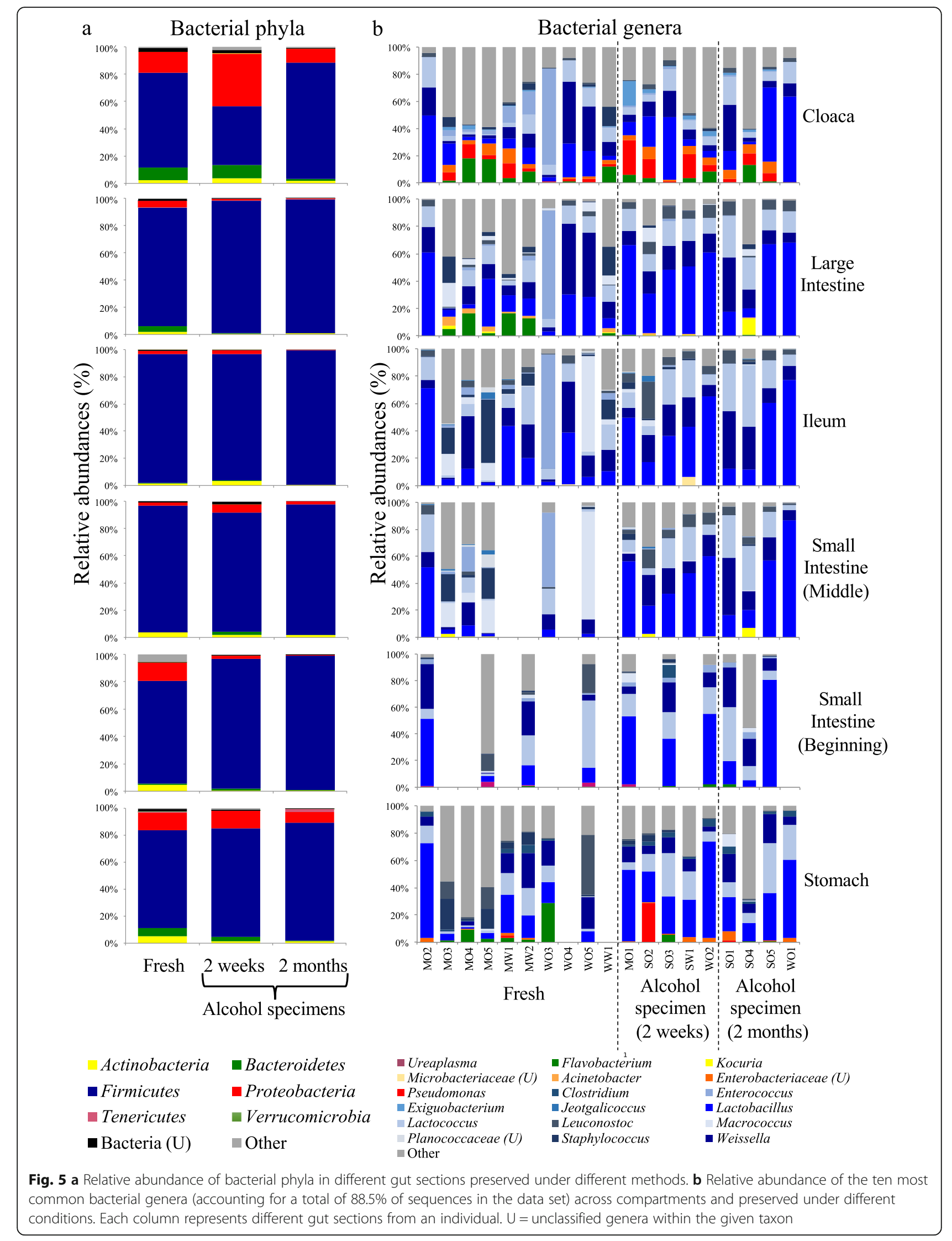


Table 2 Results of Adonis (bold) and pairwiseAdonis (Bray-Curtis distances) analyses of gut microbial communities of digestive tract regions of fresh (OD), two-weeks old (2 W), and two-months $(2 \mathrm{M})$ old alcohol specimen

\begin{tabular}{|c|c|c|c|c|}
\hline & Comparison & $F$ & $R^{2}$ & $\boldsymbol{P}$ adjust \\
\hline Cloaca $\left(\mathrm{df}_{2,18}\right)$ & & 1.144 & 0.1251 & 0.268 \\
\hline \multirow[t]{3}{*}{ Pair-wise Adonis } & OD vs. $2 \mathrm{~W}$ & 1.035 & 0.0794 & 1 \\
\hline & $2 \mathrm{~W}$ vs. $2 \mathrm{M}$ & 1.173 & 0.1435 & 0.720 \\
\hline & OD vs. $2 \mathrm{M}$ & 1.479 & 0.1185 & 0.477 \\
\hline Large Intestine $\left(\mathrm{df}_{2,18}\right)$ & & 1.144 & 0.1251 & 0.245 \\
\hline \multirow[t]{3}{*}{ Pair-wise Adonis } & OD vs. $2 \mathrm{~W}$ & 0.9088 & 0.0653 & 1 \\
\hline & $2 \mathrm{~W}$ vs. $2 \mathrm{M}$ & 1.614 & 0.1873 & 0.270 \\
\hline & OD vs. $2 \mathrm{M}$ & 0.0866 & 0.0866 & 0.993 \\
\hline Ilium $\left(\mathrm{df}_{2,18}\right)$ & & 1.579 & 0.1649 & 0.088 \\
\hline \multirow[t]{3}{*}{ Pair-wise Adonis } & OD vs. $2 \mathrm{~W}$ & 1.326 & 0.0925 & 0.549 \\
\hline & $2 \mathrm{~W}$ vs. $2 \mathrm{M}$ & 0.7268 & 0.0941 & 1 \\
\hline & OD vs. $2 \mathrm{M}$ & 2.247 & 0.1577 & 0.108 \\
\hline Middle of Small Intestine $\left(\mathbf{d f}_{2,14}\right)$ & & 2.562 & 0.2992 & $0.003^{*}$ \\
\hline \multirow[t]{3}{*}{ Pair-wise Adonis } & OD vs. $2 \mathrm{~W}$ & 1.441 & 0.1379 & 0.420 \\
\hline & $2 \mathrm{~W}$ vs. $2 \mathrm{M}$ & 3.815 & 0.3527 & 0.06 \\
\hline & OD vs. $2 \mathrm{M}$ & 3.097 & 0.2791 & $0.021^{*}$ \\
\hline Beginning of Small Intestine $\left(\mathrm{df}_{2,9}\right)$ & & 1.253 & 0.2637 & 0.219 \\
\hline \multirow[t]{3}{*}{ Pair-wise Adonis } & OD vs. $2 \mathrm{~W}$ & 1.782 & 0.2627 & 0.492 \\
\hline & $2 \mathrm{~W}$ vs. $2 \mathrm{M}$ & 0.8224 & 0.1705 & 1 \\
\hline & OD vs. $2 \mathrm{M}$ & 1.197 & 0.1931 & 0.867 \\
\hline Stomach $\left(\mathrm{df}_{2,17}\right)$ & & 1.239 & 0.1418 & 0.198 \\
\hline \multirow[t]{3}{*}{ Pair-wise Adonis } & OD vs. $2 \mathrm{~W}$ & 1.035 & 0.0794 & 1 \\
\hline & $2 \mathrm{~W}$ vs. $2 \mathrm{M}$ & 1.173 & 0.1435 & 0.720 \\
\hline & OD vs. $2 \mathrm{M}$ & 1.479 & 0.1185 & 0.477 \\
\hline
\end{tabular}

*indicates significant differences

euthanized using $\mathrm{CO}_{2}$ chambers, following the guidelines of the Czech Republic's dispensation of the law no. 359/ 2012 Col., $\mathbb{\$} 17$, par. 1 (i.e., animal cruelty act). P. major were captured and raised in captivity under the permit number OOZP/5345/2018/R La issued by Environmental Protection Department and were euthanized under the permit number MZP/2018/785/1363 issued by the Ministry of the Environment of the Czech Republic. Digestive tracts from 10 randomly chosen individuals were dissected immediately after euthenization on a sterile surface and separated into six main regions (stomach, beginning of the small intestine, middle of the small intestine, ileum including ceca, large intestine, cloaca). Gut sections were stored in RNAlater at $-21^{\circ} \mathrm{C}$ until DNA extractions.

The remaining nine birds were preserved as whole specimens in 70\% ethanol. Of these alcohol specimens, five were dissected after two weeks and four were dissected after two months. After dissection, the gut sections were stored in RNAlater at $-21^{\circ} \mathrm{C}$ until the DNA extractions. After the acquisition of digestive tract all the specimens are deposited in the alcohol bird collections of the Natural History
Museum of Denmark, Copenhagen, Denmark (For NHMID numbers, see Additional file 2: Table S6).

\section{Molecular methods}

Prior to DNA extractions, individual gut sections were mixed thoroughly using sterile pestles and $100 \mu \mathrm{l}$ of this homogeneous mixture was used for the DNA extractions. The entire tip of the swab along with $100 \mu \mathrm{l}$ of RNAlater was used to extract DNA from the cloacal swabs. DNA was extracted using Qiagen blood and tissue DNeasy kits (Qiagen, Germany), following the manufactures guidelines, except that we added mini glass beads during the lysis step to increase the physical lysis of bacterial cells and we incubated the samples (along with proteinase $\mathrm{K}$ and ATL buffer) for $12 \mathrm{~h}$ at $56^{\circ} \mathrm{C}$. We also used $75 \mu \mathrm{l}$ heated $\left(50^{\circ} \mathrm{C}\right)$ elution buffer to elute the DNA.

Initial PCRs were conducted using SA511 and SB701 primers targeting the $\mathrm{v} 4$ region of the $16 \mathrm{~S}$ rRNA gene to identify the samples with bacterial DNA (cf. [37]). PCR reactions contained total of $25 \mu \mathrm{l}(1 \mu \mathrm{l}$ of reverse primer, $1 \mu \mathrm{l}$ forward primer, $12.5 \mu \mathrm{l}$ of VWR red $\mathrm{Taq}^{\circ}$ polymerase, 


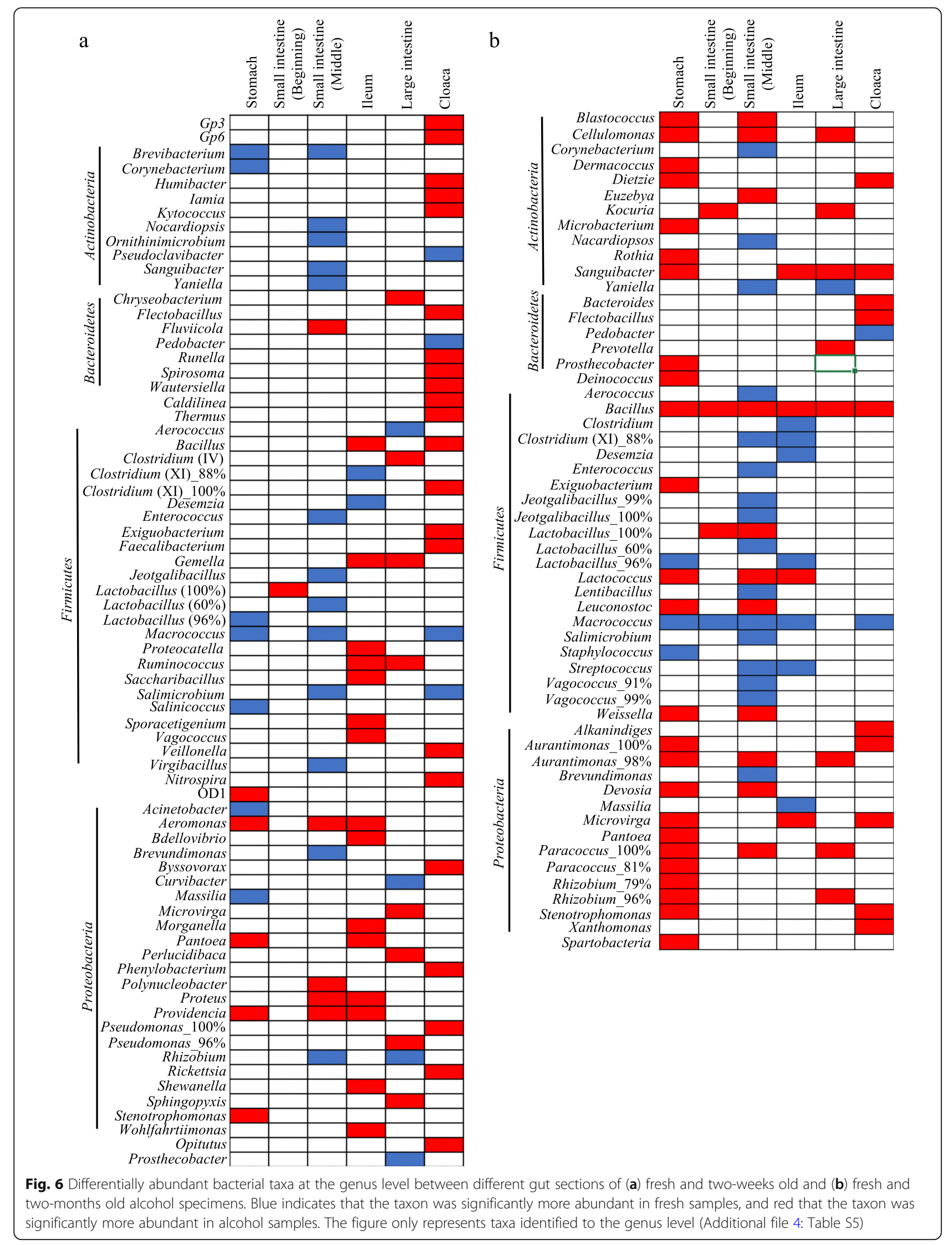


8.5 $\mu \mathrm{l}$ of MilliQ water and $2 \mu \mathrm{l}$ of DNA) and PCRs were conducted under an initial denaturing condition of $96^{\circ} \mathrm{C}$ for $4 \mathrm{~min}$, followed by 35 cycles of denaturing $\left(94^{\circ} \mathrm{C}\right.$ for $30 \mathrm{~s})$, annealing $\left(56^{\circ} \mathrm{C} 30 \mathrm{~s}\right)$ and extension $\left(72^{\circ} \mathrm{C}\right.$ for $\left.30 \mathrm{~s}\right)$ and an a final extension step of $72{ }^{\circ} \mathrm{C}$ for $4 \mathrm{~min}$. DNA from the successfully amplified samples (after visual inspection of products on a $2 \%$ agarose gel) were sent to the Microbial System Molecular Biology Lab at the University of Michigan for MiSeq amplicon sequencing (using the same primers) on an Illumina platform.

\section{Data analysis}

MiSeq sequences were analyzed using mothur 1.35.1 [45]. Chimeric and non-prokaryotic sequences were removed following the mothur pipeline. Cleaned sequences were aligned and identified using the SILVA 132 database [46]. Samples containing less than 1000 sequences were removed from the analysis. Downstream analyses were conducted in R 3.5.3 [47, 48]. Alpha diversity (OTU richness, Chao 1 richness estimate, Shannon diversity index and inverse Simpson's diversity index), Permutational multivariate analysis of variance (PERMANOVA) based on Bray-Curtis (with abundances) and Jaccard distance matrixes (presence/ absence of OTUs), and non-matric multidimensional scaling (NMDS) analyses were conducted using the vegan package [49]. For pair-wise PERMANOVAs, we used the wrapper package pairwiseAdonis [50]. Tukey HSD post hoc tests were conducted to investigate pairwise statistically significant differences in alpha diversity between digestive tract regions (including cloacal swabs) and gut regions under different storing conditions. DeSeq2 [51] was utilized within the MicrobiomeSeq package [52] along with Phyloseq package [53] to investigate significantly differentially abundant bacterial genera between samples.

\section{Supplementary information}

Supplementary information accompanies this paper at https://doi.org/10. 1186/s42523-020-00026-8.

Additional file 1: Table S1. OTU table of all samples, categorized according to the sample region and preservation method (freshly dissected, two-weeks old and two-month alcohol specimens).

Additional file 2: Table S2. Results of pairwiseAdonis analysis between gut microbial communities of major gut regions [the stomach, the midgut (the small intestine and the cecum), and the hindgut (large intestine and (loaca)] and cloacal swabs. Asterisks indicate sections that were significantly different in composition. Table S3. The results of pairwiseAdonis analyses using Jaccard distances between gut microbial communities of different regions of the digestive tract (including cloacal swabs). Table S4. Summary of one-way analysis of variance (ANOVA) on OTU richness (R), Chao1 richness estimate (C), Shannon's diversity index (Sh) and Inverse Simpson's diversity index (Isimp) of freshly dissected gut sections and alcohol preserved specimens. Table S6. Museum ID numbers (Natural History Museum of Denmark), sexes and treatments (freshly dissected, two-weeks old alcohol specimens and two-months old alcohol specimens) of the 19 P. major used in this study.
Additional file 3: Figure S1. NMDS plots of microbial community similarities between different gut sections of fresh and differently aged alcohol samples. Ellipses represent 95\% confidence intervals.

Additional file 4: Table S5. Results from the DeSeq2 analysis on differentially abundant bacterial genera between fresh and differently aged alcohol specimens. Each tab includes data from one region of the digestive tract.

\section{Acknowledgements}

We thank Inga Freiberga for assistance with bird rearing.

\section{Authors' contributions}

$\mathrm{KHB}, \mathrm{KAJ}$ and MP developed the idea. KS and KP took care of the birds. KHB conducted the molecular work and the data analyses. KHB, KAJ and MP wrote the initial manuscript with comments from KS and KP. All authors read and approved the final manuscript.

\section{Funding}

We thank the Carlsberg Foundation for financial support through a Distinguished Associate Professor Fellowship to KAJ (CF17-0248). We also thank the Grant Agency of the Czech Republic (18-23794Y) and the Grant Agency of the University of South Bohemia (GAJU n.048/2019/P) for funding to $\mathrm{KS}$ and $\mathrm{KP}$.

\section{Availability of data and materials}

The datasets generated and analyzed during the current study are available in the GenBank SRA repository (SRA accession: PRJNA591550, Bio sample accession numbers [gut sections]: SAMN13383021 - SAMN13383134, Cloacal swab accession numbers: SRR9295628, SRR9295605, SRR9295561, SRR9295668, SRR9295635, SRR9295590, SRR9295610, SRR9295576, SRR9295676, SRR9295651, SRR9295639, SRR9295585).

\section{Ethics approval}

Birds were captured and raised in captivity under the permit number OOZP/ 5345/2018/R La issued by Environmental Protection Department of Czech Republic. Bird were euthanized (using a $\mathrm{CO}_{2}$ chamber) following the guidelines of the Czech Republic's dispensation of the law no. 359/2012 Col., $\S 17$, par. 1 (i.e., animal cruelty act) under the permit number MZP/2018/785/ 1363 issued by Ministry of the Environment of the Czech Republic.

\section{Competing interests}

The authors declare that they have no competing interests.

\section{Author details}

${ }^{1}$ Natural History Museum of Denmark, University of Copenhagen, Copenhagen, Denmark. 'Biology Centre of Czech Academy of Sciences, Institute of Entomology, Branisovska 31, Ceske Budejovice, Czech Republic. ${ }^{3}$ Faculty of Science, University of South Bohemia, Branisovska 1760, Ceske Budejovice, Czech Republic. ${ }^{4}$ Section for Ecology and Evolution, Department of Biology, University of Copenhagen, Copenhagen, Denmark.

Received: 20 December 2019 Accepted: 25 February 2020 Published online: 17 March 2020

\section{References}

1. Song SJ, Amir A, Metcalf JL, Amato KR, Xu ZZ, Humphrey G, Knight R. Preservation methods differ in fecal microbiome stability, affecting suitability for field studies. mSystems. 2016;1(3):e00021-16. https://doi.org/10.1128/ mSystems.00021-16.

2. Videvall E, Strandh M, Engelbrecht A, Cloete S, Cornwallis CK. Measuring the gut microbiome in birds: comparison of faecal and cloacal sampling. Mol Ecol Resour. 2018;18(3):424-34.

3. Blaser M, Bork P, Fraser C, Knight R, Wang J. The microbiome explored: recent insights and future challenges. Nat Rev Microbiol. 2013;11(3):213-7.

4. Hale VL, Tan CL, Knight R, Amato KR. Effect of preservation method on spider monkey (Ateles geoffroyi) fecal microbiota over 8 weeks. J Microbiol Meth. 2015;113:16-26.

5. Drovetski SV, O'Mahoney M, Ransome EJ, Matterson KO, Lim HC, Chesser RT, Graves GR. Spatial organization of the gastrointestinal microbiota in urban 
Canada geese. Sci Rep. 2018;8:3713. https://doi.org/10.1038/s41598-01821892-y.

6. King GM, Judd C, Kuske CR, Smith C. Analysis of stomach and gut microbiomes of the eastern oyster (Crassostrea virginica) from coastal Louisiana, USA. Plos One. 2012;7(12):e51475. https://doi.org/10.1371/journal. pone.0051475.

7. Liu Y, Zheng ZJ, Yu LH, Wu S, Sun L, Wu SL, Xu Q, Cai SF, Qin N, Bao WB. Examination of the temporal and spatial dynamics of the gut microbiome in newborn piglets reveals distinct microbial communities in six intestinal segments. Sci Rep. 2019;9:3453. https://doi.org/10.1038/s41598-019-40235-z.

8. Pauli JN, Whiteman JP, Riley MD, Middleton AD. Defining noninvasive approaches for sampling of vertebrates. Conserv Biol. 2010;24(1):349-52.

9. Colston TJ, Jackson CR. Microbiome evolution along divergent branches of the vertebrate tree of life: what is known and unknown. Mol Ecol. 2016; 25(16):3776-800

10. Muegge BD, Kuczynski J, Knights D, Clemente JC, Gonzalez A, Fontana L, Henrissat B, Knight R, Gordon J. Diet drives convergence in gut microbiome functions across mammalian phylogeny and within humans. Science. 2011; 332(6032):970-4.

11. Kropackova L, Tesicky M, Albrecht T, Kubovciak J, Cizkova D, Tomasek O, Martin JF, Bobek L, Kralova T, Prochazka P, et al. Codiversification of gastrointestinal microbiota and phylogeny in passerines is not explained by ecological divergence. Mol Ecol. 2017;26(19):5292-304.

12. Wei FW, Wang X, Wu Q. The giant panda gut microbiome. Trends Microbiol. 2015;23(8):450-2.

13. Zhao GH, Zhou LZ, Dong YQ, Cheng YY, Song YW. The gut microbiome of hooded cranes (Grus monacha) wintering at Shengjin Lake, China. Microbiologyopen. 2017;6(3):e00447. https://doi.org/10.1002/mbo3.447.

14. Waite DW, Deines P, Taylor MW. Gut microbiome of the critically endangered New Zealand parrot, the Kakapo (Strigops habroptilus). PLoS One. 2012;7(4):e35803. https://doi.org/10.1371/journal.pone.0035803.

15. Barelli C, Albanese D, Donati C, Pindo M, Dallago C, Rovero F, Cavalieri D, Tuohy KM, Hauffe HC, De Filippo C. Habitat fragmentation is associated to gut microbiota diversity of an endangered primate: implications for conservation. Sci Rep. 2015;5:14862. https://doi.org/10.1038/srep14862

16. Kropackova L, Pechmanova H, Vinkler M, Svobodova J, Velova H, Tesicky M, Martin JF, Kreisinger J. Variation between the oral and faecal microbiota in a free-living passerine bird, the great tit (Parus major). PLoS One. 2017;12(6): e0179945. https://doi.org/10.1371/journal.pone.0179945.

17. Garcia-Mazcorro JF, Castillo-Carranza SA, Guard B, Gomez-Vazquez JP, Dowd $\mathrm{SE}$, Brigthsmith DJ. Comprehensive molecular characterization of bacterial communities in feces of pet birds using 165 marker sequencing. Microb Ecol. 2017;73(1):224-35.

18. Grond K, Santo Domingo JW, Lanctot RB, Jumpponen A, Bentzen RL, Boldenow ML, Brown SC, Casler B, Cunningham JA, Doll AC, et al. Composition and drivers of gut microbial communities in Arctic-breeding shorebirds. Front Microbiol. 2019;10:2258. https://doi.org/10.3389/fmicb. 2019.02258.

19. Dewar ML, Arnould JPY, Dann P, Trathan P, Groscolas R, Smith S. Interspecific variations in the gastrointestinal microbiota in penguins. Microbiologyopen. 2013;2(1):195-204.

20. Dewar ML, Arnould JPY, Krause L, Dann P, Smith SC. Interspecific variations in the faecal microbiota of Procellariiform seabirds. FEMS Microbiol Ecol. 2014;89(1):47-55

21. Risely A, Waite D, Ujvari B, Klaassen M, Hoye B. Gut microbiota of a longdistance migrant demonstrates resistance against environmental microbe incursions. Mol Ecol. 2017;26(20):5842-54.

22. Risely A, Waite DW, Ujvari B, Hoye BJ, Klaassen M. Active migration is associated with specific and consistent changes to gut microbiota in Calidris shorebirds. J Anim Ecol. 2018;87(2):428-37.

23. Kreisinger J, Cizkova D, Kropackova L, Albrecht T. Cloacal microbiome structure in a long-distance migratory bird assessed using deep 16sRNA pyrosequencing. PLoS One. 2015;10(9):e0137401. https://doi.org/10.1371/ journal.pone.0137401.

24. Musitelli F, Ambrosini R, Rubolini D, Saino N, Franzetti A, Gandolfi I. Cloacal microbiota of barn swallows from northern Italy. Ethol Ecol Evol. 2018;30(4): 362-72.

25. Ambrosini R, Corti M, Franzetti A, Caprioli M, Rubolini D, Motta VM, Costanzo A, Saino N, Gandolfi I. Cloacal microbiomes and ecology of individual barn swallows. Fems Microbiol Ecol. 2019;95(6):fiz061. https://doi. org/10.1093/femsec/fiz061.
26. Barbosa A, Balague V, Valera F, Martinez A, Benzal J, Motas M, Diaz Jl, Mira A, Pedros-Alio C. Age-related differences in the gastrointestinal microbiota of chinstrap penguins (Pygoscelis antarctica). PLoS One. 2016;11(4):e0153215. https://doi.org/10.1371/journal.pone.0153215.

27. van Dongen WFD, White J, Brandl HB, Moodley Y, Merkling T, Leclaire S, Blanchard P, Danchin E, Hatch SA, Wagner RH. Age-related differences in the cloacal microbiota of a wild bird species. BMC Ecol. 2013;13:11. https:// doi.org/10.1186/1472-6785-13-11.

28. Merkeviciene L, Ruzauskaite N, Klimiene I, Siugzdiniene R, Dailidaviciene J, Virgailis M, Mockeliunas R, Ruzauskas M. Microbiome and antimicrobial resistance genes in microbiota of cloacal samples from European herring gulls (Larus argentatus). J Vet Res. 2017;61(1):27-35.

29. Klomp JE, Murphy MT, Smith SB, Mckay JE, Ferrera I, Reysenbach AL. Cloacal microbial communities of female spotted towhees Pipilo maculatus: microgeographic variation and individual sources of variability. J Avian Biol. 2008;39(5):530-8.

30. Drovetski SV, O'Mahoney MJV, Matterson KO, Schmidt BK, Greves GR. Distinct microbiotas of anatomical gut regions display idiosyncratic seasonal variation in an avian folivore. BMC Anim Microbiome. 2019;1:2. https://doi. org/10.1186/s42523-019-0002-6.

31. Garcia-Amado MA, Shin H, Sanz V, Lentino M, Martinez LM, Contreras M, Michelangeli F, Dominguez-Bello MG. Comparison of gizzard and intestinal microbiota of wild neotropical birds. PLoS One. 2018;13(3):e0194857. https:// doi.org/10.1371/journal.pone.0194857.

32. Zhang Y, Simon SE, Johnson JA, Allen MS. Spatial microbial composition along the gastrointestinal tract of captive Attwater's prairie chicken. Microb Ecol. 2017;73(4):966-77.

33. Stanley D, Geier MS, Chen H, Hughes RJ, Moore RJ. Comparison of fecal and cecal microbiotas reveals qualitative similarities but quantitative differences. BMC Microbiol. 2015;15:51. https://doi.org/10.1186/s12866015-0388-6

34. Youngblut ND, Reischer GH, Walters W, Schuster N, Walzer C, Stalder G, Ley $\mathrm{RE}$, Farnleitner AH. Host diet and evolutionary history explain different aspects of gut microbiome diversity among vertebrate clades. Nat Commun. 2019;10:2200. https://doi.org/10.1038/s41467-019-10191-3.

35. Grond K, Sandercock BK, Jumpponen A, Zeglin LH. The avian gut microbiota: community, physiology and function in wild birds. J Avian Biol. 2018;49(11):e01788. https://doi.org/10.1111/jav.01788.

36. Hird SM. Evolutionary biology needs wild microbiomes. Front Microbiol. 2017:8:725. https://doi.org/10.3389/fmicb.2017.00725.

37. Bodawatta KH, Sam K, Jonsson KA, Poulsen M. Comparative analyses of the digestive tract microbiota of new Guinean passerine birds. Front Microbiol. 2018;9:1830. https://doi.org/10.3389/fmicb.2018.01830.

38. Lutz HL, Tkach W, Weckstein JD. Methods for specimen-based studies of avian symbionts 1. In: Webster MS, editor. The extended specimen emerging frontiers in collections-based ornithological research. Boca Raton: CRC Press, Taylor and Francis Group; 2017.

39. Roselaar CS. An inventory of major European bird collections. Bull B O C. 2003:123:253-337.

40. Banks C, Clench MH, Barlow JC. Bird collections in the United States and Canada. Auk. 1973;90:136-70.

41. Gill BJ. Birds in Australian and New Zealand museums - a major resource for ornithology. New Zeal J Zool. 2006;33(4):299-315.

42. Eriksson P, Mourkas E, González-Acuna D, Olsen B, Ellström P. Evaluation and optimization of microbial DNA from fecal samples an of wild Antarctic birds species. Infect Ecol Epidemiol. 2017;7(1):1386536. https://doi.org/10.1080/ 20008686.2017.1386536.

43. Regnaut S, Lucas FS, Fumagalli L. DNA degradation in avian faecal samples and feasibility of non-invasive genetic studies of threatened capercaillie populations. Conserv Genet. 2006;7(3):449-53.

44. Waite DW, Taylor MW. Exploring the avian gut microbiota: current trends and future directions. Front Microbiol. 2015;6:673. https://doi.org/10.3389/ fmicb.2015.00673.

45. Kozich JJ, Westcott SL, Baxter NT, Highlander SK, Schloss PD. Development of a dual-index sequencing strategy and curation pipeline for analyzing amplicon sequence data on the MiSeq Illumina sequencing platform. Appl Environ Microb. 2013;79(17):5112-20.

46. Quast C, Pruesse E, Yilmaz P, Gerken J, Schweer T, Yarza P, Peplies J, Glockner FO. The SILVA ribosomal RNA gene database project: improved data processing and web-based tools. Nucleic Acids Res. 2013:41(D1):D590-6 
47. Team RC. R: a language and environment for statistical computing. Vienna: R Foundation for Statistical Computing; 2019. https://www.R-project.org/. Accessed 10 June 2019.

48. Team R. RStudio: integrated development for R. Boston: RStudio, Inc; 2015. http://www.rstudio.com/. Accessed 10 June 2019.

49. Oksanen J, Blanchet FG, Friendly M, Kindt R, Legendre P, McGlinn D, Minchin PR, O'Hara RB, Simpson GL, Solymos P, Stevens MHH, Szoecs E, Wagner $\mathrm{H}$. vegan: community ecology package. $\mathrm{R}$ package version 2.5-4. 2019. https://CRAN.R-project.org/package=vegan. Accessed 10 June 2019.

50. Arbizu MP. pairwiseAdonis: pairwise multilevel comparison using adonis. 2019. https://github.com/pmartinezarbizu/pairwiseAdonis. Accessed 10 June 2019.

51. Love MI, Huber W, Anders S. Moderated estimation of fold change and dispersion for RNA-seq data with DESeq2. Genome Biol. 2014;15(12):550. https://doi.org/10.1186/s13059-014-0550-8.

52. Ssekagiri A, Sloan WT, Ljaz UZ: microbiomeSeq: an R package for microbial community analysis in an environmental contex. 2018. http://www.github. com/umerijaz/microbiomeSeq. Accessed 10 June 2019.

53. McMurdie PJ, Holmes S. phyloseq: an R package for reproducible interactive analysis and graphics of microbiome census data. PLoS One. 2013;8(4): e61217. https://doi.org/10.1371/journal.pone.0061217.

\section{Publisher's Note}

Springer Nature remains neutral with regard to jurisdictional claims in published maps and institutional affiliations.

Ready to submit your research? Choose BMC and benefit from:

- fast, convenient online submission

- thorough peer review by experienced researchers in your field

- rapid publication on acceptance

- support for research data, including large and complex data types

- gold Open Access which fosters wider collaboration and increased citations

- maximum visibility for your research: over $100 \mathrm{M}$ website views per year

At $\mathrm{BMC}$, research is always in progress.

Learn more biomedcentral.com/submissions 